\title{
REPEATED LOADING OF COHESIVE SOIL - SHAKEDOWN THEORY IN UNDRAINED CONDITIONS
}

\author{
ANDRZEJ GŁUCHOWSKI, ALOJZY SZYMAŃSKI, WOJCIECH SAS \\ Warsaw University of Life Sciences - SGGW, Faculty of Civil and Environmental Engineering, \\ ul. Nowoursynowska 159, 02-776 Warszawa, Poland, \\ e-mail: andrzej_gluchowski@gssw.pl,wojciech_sas@sggw.pl, alojzy_szymanski@sggw.pl
}

\begin{abstract}
The development of industry and application of new production techniques could bring about extraordinary problems that have been neglected. One of these challenges in terms of soil mechanics is high frequency cyclic loading. Well constructed foundation may reduce this troublesome phenomenon but excluding it is usually uneconomic.

In this paper, shakedown theory assumptions were studied. Cyclically loaded soils behave in various ways depending on the applied stress rate. Common cohesive soils in Poland, i.e., sandy-silty clays are problematic and understanding of their behaviour in various conditions is desired. In order to study repeated loading of this material, cyclic triaxial test were carried out. Cyclic loading tests were conducted also in one way compression. These methods in small strain regime allow permanent strain increment analysis with resilient response after numerous cycles. This behaviour was subsequently exploited in the study of shakedown theory. This paper contains some conclusions concerning the above-mentioned theory.
\end{abstract}

Key words: cyclic, triaxial test, clay, shakedown, undrained, resilient modulus

\section{INTRODUCTION}

The phenomenon of porous material fatigue due to cyclic loads beyond failure loads is well recognized [2], [10], [12]. However, the occurrence of plastic strain in a structure may not cause failure even after numerous repetitions. It is obvious that such behaviour of soil subjected to cyclic loading is dependent on stress rate [15], [20]. Furthermore, such properties as amplitude, frequency of load and physical behaviour became clarified. It was observed in many tests that there exists a limit stress which causes different response due to repeated loading [25]. This threshold stress is called the critical stress and under this value cyclically loaded soil will show no further development of permanent strains and after some limited number of repetitions will behave purely elastically. This critical limit is referred to shakedown theory and is classified as shakedown [18]. This theory is used to find the critical point of bearing capacity of a structure under cyclic loads.

Researchers have reported many such cases when soil subjected to repeated excitations responds with equilibrium state after numerous repetitions in contrast to first ten cycles during which rapid displacements are observed [4], [17]. Equilibrium state can be reached in soils under plastic strain increment accumulation after numerous cycles. The occurrence of plastic strains even after 20000 load cycles is called "plastic shakedown" [21], [23].

Shakedown theory was first introduced by Melan [11] for constructions under static load. Later, for static conditions shakedown kinematic theory was introduced by Koiter [8]. In geotechnical engineering, including first reports by Sharp and Brooker [18] shakedown was applied to the stability of soil structures. Further studies concern pavement and offshore foundations [16], [26]. Of great importance as regards soils is unusual, in comparison with concrete or steel, plastic flow which results in unclear shakedown limits.

To simplify the mathematical description of shakedown behaviour, application of the traditional elastoplastic analysis together with the recognition criterion of shakedown models was proposed [6].

The shakedown of soil was also observed in studies on cyclic unconfined compressive strength test and on cyclic CBR test [5], [19].

The purpose of this paper is to find shakedown limit and establish relationships which may clarify the behaviour of soil under cyclic loading. Previous research [6], [1] concentrated on the development of shakedown theory using the Druker-Pager and Mohr-Coulomb yield criteria in finite element models. 
In the present study, small strains were applied to soil sample in a cyclic manner causing the specimen to reach elastic shakedown. This phenomenon is called the lower bound dynamic shakedown. Research was carried out on cyclic triaxial equipment on compacted clayey samples applying Proctor's method.

Tests were conducted on cohesive soil samples which are common soils in northern part of Poland which lie on the surface and become base of pavements and shallow foundations.

\section{SHAKEDOWN THEORY}

Shakedown theory is proposed as a method of analysis of the plastic collapse of soil subjected to variable loads. Unlike with the static load when limit analysis is employed to obtain proper design values, cyclic loading of material such as soils needs to be treated in different manner. Shakedown limit provides a rational criterion for design purposes [9].

As was mentioned above, shakedown limit can be utilised as critical shakedown load criterion for designed materials. Numerous studies dedicated to compute lower and upper bounds of critical shakedown load with application of finite element method software and a linear programming procedure were conducted [27], [3]. Repeated Loading Tests (RLT) conducted on unbound granular materials which are commonly utilised as pavement subbase were studied for the purpose of applying shakedown theory. The proposed criterion [22], [23] for unbound granular materials relates shakedown limits with vertical strains, especially when vertical plastic strain is plotted against vertical strains in each cycle. Soil loaded with cyclic force response behaves in one of the four possible ways:

1. Elastic response - in the case of sufficiently low loading levels, where no permanent strain accumulation occurs.

2. Elastic shakedown - the repeated load is high enough to cause plastic strains but still low to reach plastic shakedown limit. At this stage, the plastic strain increment is finite and after certain number of cyclic loads the elastic response will be restored.

3. Plastic shakedown describes phenomena of repeated loading of soil where plastic strain occurs after numerous repetitions. Nevertheless, the material achieves long-term steady state response. In other words, soil becomes purely resilient after completion of the post-compaction.
4. Plastic creep also called as intermediate response, where the level of permanent strain rate decreases in the first several load cycles to a low and nearly constant level.

\section{MATERIAL}

In this study, material which was used for tests was cohesive soil taken from the road construction site. For the purpose of ensuring good specimen reproducibility, an artificial soil is used for the tests. For all the samples, conditions of water content in compaction procedure was maintained. The compaction, with respect to the Proctor method, was chosen because of typical engineering application preservation. Optimal moisture content was $w_{\text {opt }}=10.58 \%$, dry density was $\rho_{\mathrm{ds}}=1.97 \mathrm{~g} / \mathrm{cm}^{3}$. Based on the sieve analysis, this soil was classified as sandy-silty clay (sasiCl). Liquid limit obtained from Casagrande apparatus was $W L=$ $22.5 \%$. Void ratio was $e=0.38$.

\section{TEST PROCEDURE}

The tests are carried out with a triaxial cell for cylindrical soil specimens with diameter equal to $7 \mathrm{~cm}$ and height of $14 \mathrm{~cm}$. The samples were fully saturated and B-value for each test was more than 0.90. Samples were then subjected to an isotropic effective confining pressure of $270 \mathrm{kPa}$ and consolidated. All specimens were normally consolidated. The deviator stress $q$ was $30 \mathrm{kPa}$ and then the specimens were unloaded to $24 \mathrm{kPa}$, the amplitude of loading being equal to $6 \mathrm{kPa}$. Repeated loading triaxial tests were conducted in a consolidated-undrained (CU) one-way cyclic loading manner. The cyclic loading was applied in vertical direction with the sine wave. The frequency of the test was equal to $1.0 \mathrm{~Hz}$. Such a cyclic stress level and initial confining pressure were used to define the effects on cyclic behavior. The number of cycles was 10000 . During the test, effective stress $p^{\prime}$ was decreasing due to an increase of the pore pressure.

\section{RESULTS}

Repeated loading triaxial test results are presented in Fig. 1 as the plots of the Cambridge deviator stress $q$ against effective mean stress $p^{\prime}$. 


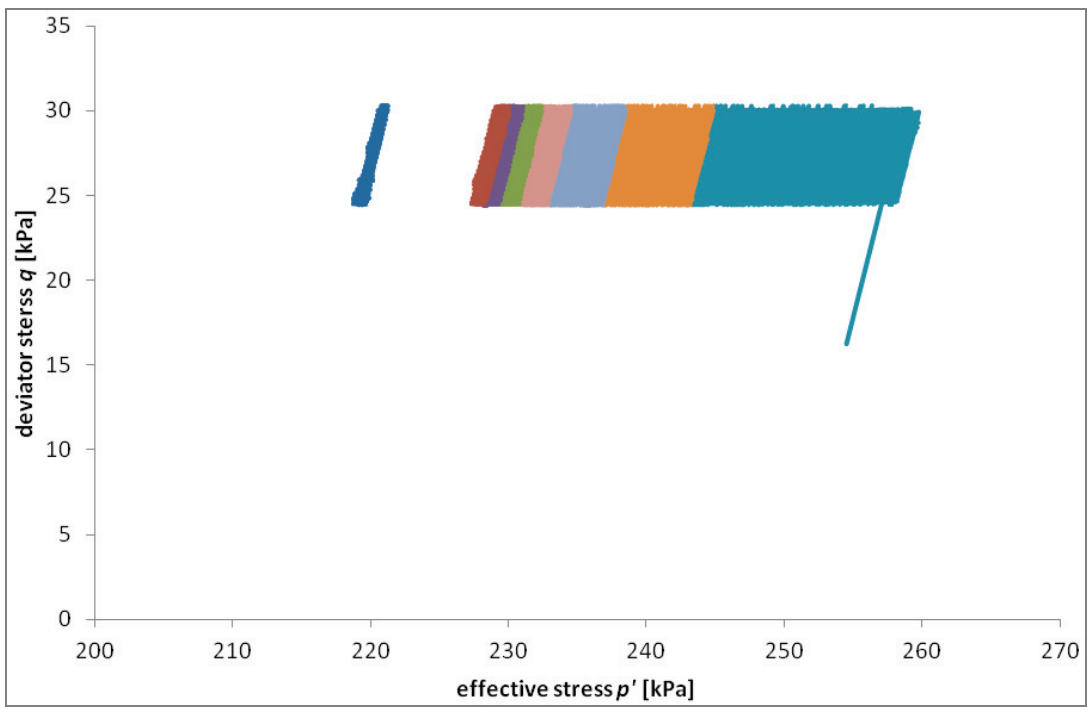

Fig. 1. Plot of effective stress and deviator stress from repeated loading triaxial test for sandy-silty clay

On this plot standard stress path was obtained. Figure 1 presents the first 2240 cycles and the last 1000 cycles. It is easy to find that stress paths tend to decrease with the mean effective stress $p^{\prime}$. Stress $p^{\prime}$ decrement is bound with an increase of the pore water pressure $u$, which relationship was reported by researchers when CU triaxial tests were conducted [24], [7]. Effective stress during tests follows the same pattern. In the first 50 cycles, the decrease of $p^{\prime}$ was high, then it stabilized, and during the last $10000 \mathrm{cy}-$ cles was reduced by $1.13 \mathrm{kPa}(0.113 \mathrm{~Pa}$ per cycle).

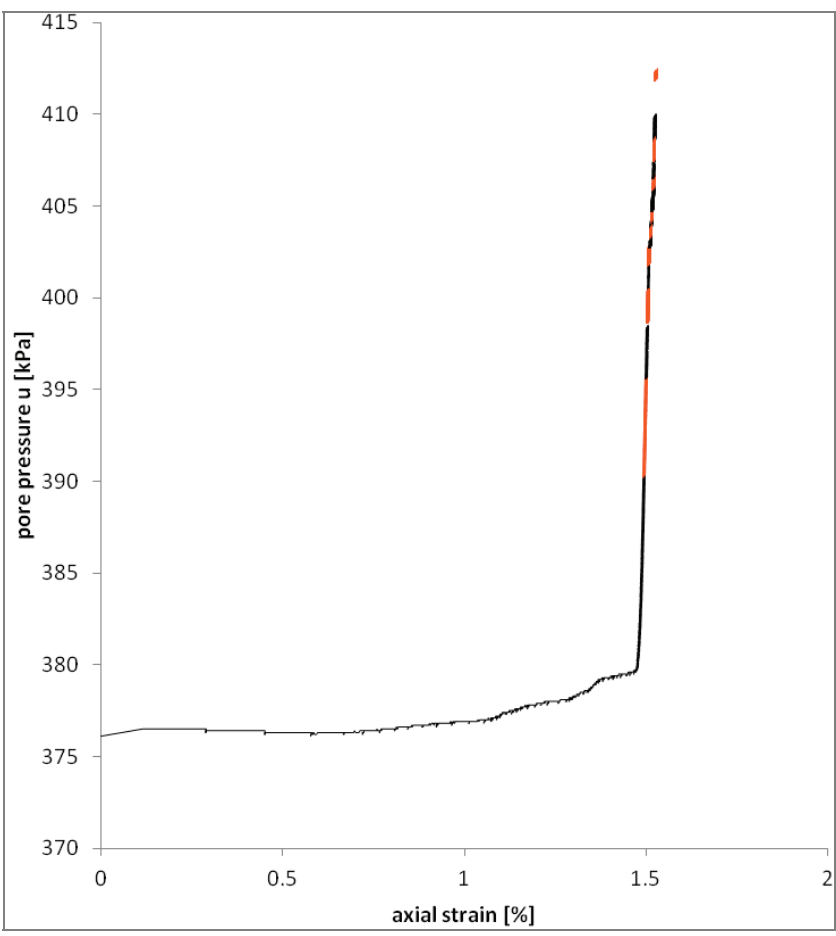

Fig. 2. Plot of pore pressure $u$ evolution during repeated loading triaxial test on sandy-silty clay sample
The phenomenon of decreasing effective stress $p^{\prime}$ as was mentioned above, in undrained conditions is bounded with the pore pressure $u$ increase. Interesting occurrence is presented in Fig. 2. The plot of pore water pressure against axial vertical strain shows two phases of cyclic loading. In the first one, pore pressure is generated with plastic strain increment. Then strain increase potential rapidly stops and only excess pore pressure is generated with the number of cycles constantly decreasing.

It is observed that less internal excess pore water pressure $\Delta u$ will be produced due to the reduction of void ratio [13].

Figure 3 presents a detailed view of hysteresis loop from repeated loading triaxial tests in selected cycles. Figure 2 can provide useful information about the end of void ratio decreasing and the threshold strain when excess pore water pressure will rapidly increase was set at $\varepsilon_{\text {trd }}=1.477 \%$. Figure 3 presents hysteresis loops that are closed, which indicates plastic shakedown occurrence. Despite this fact, plastic strain still occurs and as was mentioned above excess pore water pressure still rises. The visible differences between the shape of hysteresis no. 100 and no. 10000 are easy to find. The 100th cycle of repeated loading seems to tend to the linear elastic response and further elastic shakedown of soil material. The 10000 th cycle is characterized by grater resilient elastic strain and more nonlinear stress paths. The reason of such behavior is that during cyclic loading before threshold strain occurs soil specimen undergoes compaction process. After compaction phase, the sample accumulates more of deviatoric stress on water pressure. Plastic strain occurrence after compaction phase causes a decrease of sample stiffness and hence an 
increase in the resilient strain. The proper presentation of this phenomenon is given in Fig. 4, where resilient modulus $M_{r}$ is plotted in consecutive loading cycles.

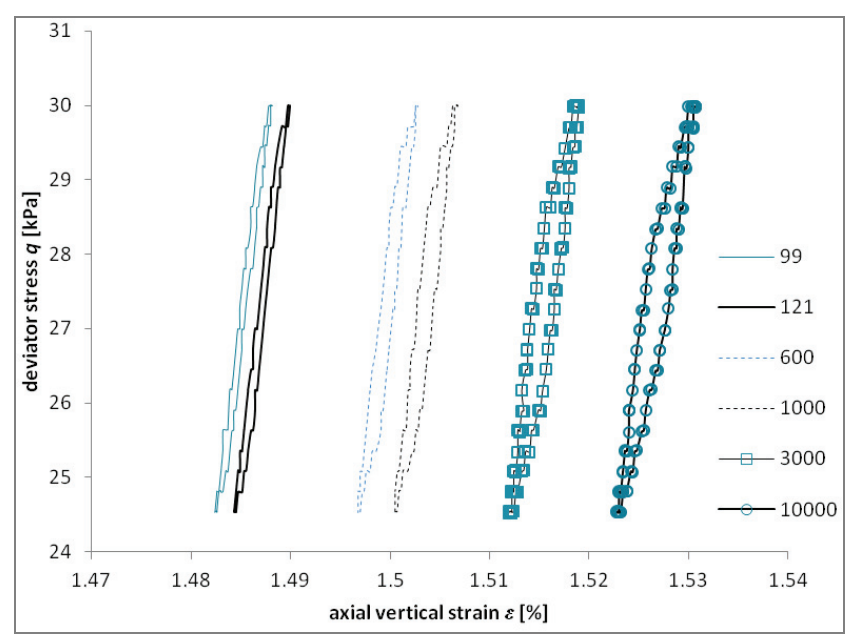

Fig. 3. Plot of detailed hysteresis loop in selected cycles during one way cyclic loading in consolidated undrained repeated loading triaxial test

Resilient modulus $M_{r}$ is defined as a quotient of cyclic stress $\Delta \sigma$ during cycle to elastic (resilient) strain $\Delta \varepsilon$ in this cycle. In the first cycle, for example, the resilient modulus was equal to $2.98 \mathrm{MPa}$. After 100 cycles, $M_{r}$ value rises up to $94.33 \mathrm{MPa}$. In the first phase, when threshold strain $\varepsilon_{\text {trd }}$ was not obtained, resilient modulus value growth was constant. During about fife cycles around threshold strain $\varepsilon_{\text {trd }}$ soil specimens sustained abrupt increase of mechanical properties in the form of resilient modulus increase. Then, in the second phase, resilient modulus rises again in a constant manner to the point of peak value equal to $101.32 \mathrm{MPa}$ at $121 \mathrm{st}$ cycle. After that $M_{r}$ value deceases in a constant manner to $69.25 \mathrm{MPa}$ at 10 000th cycle.

Figure 4 also predicts a decrement of resilient modulus in numerous cycles. The decrease of $M_{r}$ characteristic is caused by resilient strain increase. Total plastic stain increment in cycles between 99 and 10000 equals $\Delta \varepsilon_{P}=0.0402 \%$ and total strain between the above mentioned boundary cycles equals $\Delta \varepsilon_{T}=0.0425 \%$, which means that the increment of the total stress is greater than the increase of the plastic strains.

Figure 5 presents a growth of vertical strain during the next cycles. An increase of strain corresponds with a decrease of resilient modulus value and increment of excess pore pressure. The observed phenomenon of strain relaxation is associated with excess pore pressure increment, which is caused by the end of compaction process and gov- erned by threshold strain on which a rapid change in mechanical performance occurred.

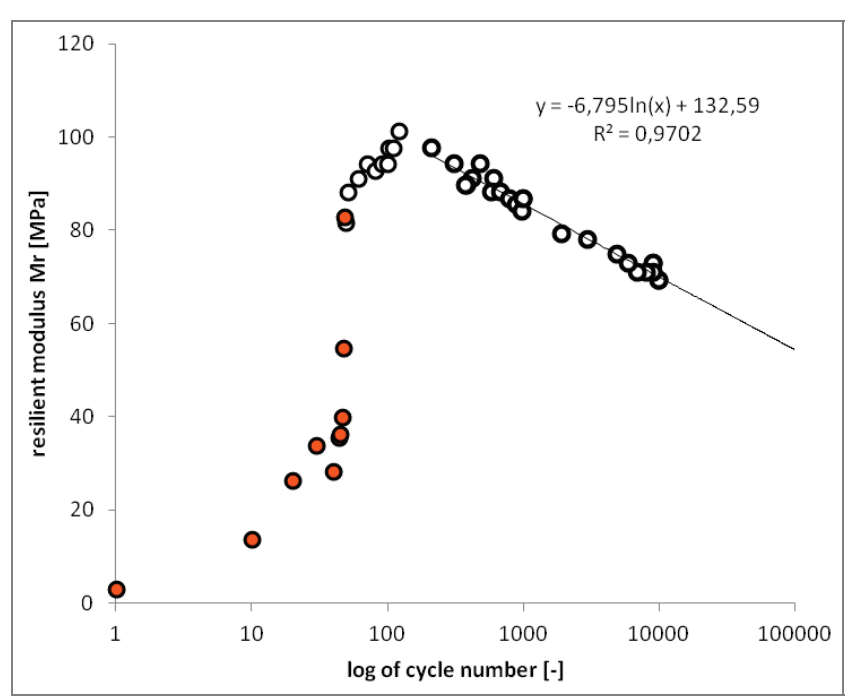

Fig. 4. Plot of the resilient modulus variability during repeated loading (complete points

- first phase, empty points - second phase)

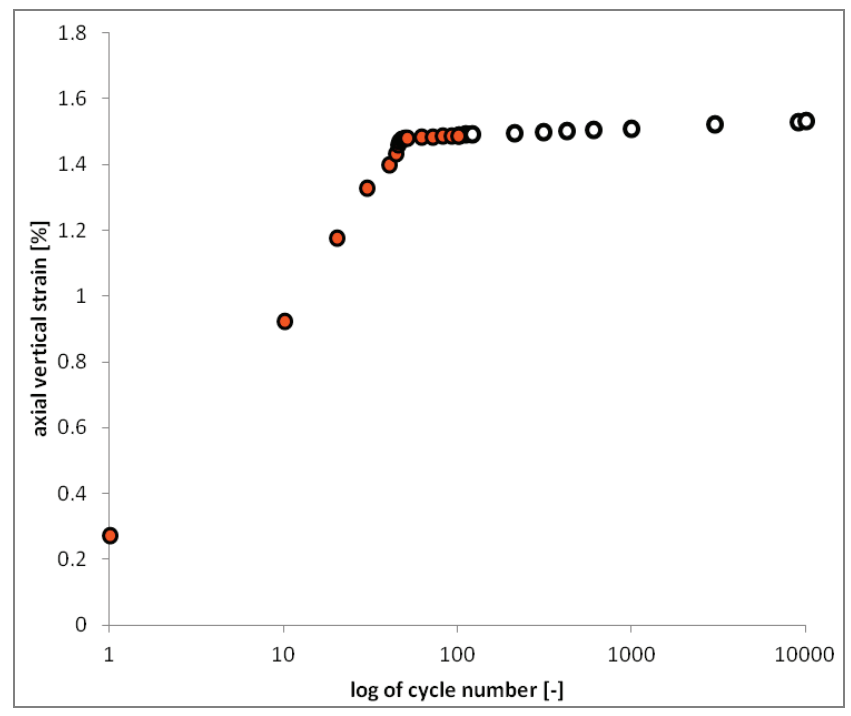

Fig. 5. Plot of the vertical strain during repeated loading test (complete points - peak resilient modulus value, empty points - phase of the resilient modulus decrement)

\section{CONCLUSIONS}

In this paper, results of cyclic triaxial test on sandysilty clay specimen which was loaded by a force caused low strains have been presented. During the test of 10000 repeated loads plastic shakedown phenomenon was noted. The data obtained from the test led to the following conclusions concerning the development of plastic shakedown in undrained conditions: 
1. Based on the tests in undrained conditions we obtained standard stress paths where effective stress $p^{\prime}$ decreases with the excess pore pressure $\Delta u$ growth. The last 1000 cycles caused a decrease of $p^{\prime}$ of about $1.13 \mathrm{kPa}$. This phenomenon could indicate that in the next cycles the excess pore pressure will still extinguish.

2. Analysing the pore pressure evolution during repeated loading we found threshold strain at which compaction process is ended and a rapid increase of mechanical properties is observed.

3. The above-mentioned compaction process relies on void ratio decreasing. The phenomenon of an increase in abrupt resilient modulus $M_{r}$ value is partially bounded with optimal density of soil in such conditions and with pore pressure increase which takes some pressure of deviator stress.

4. The process of repeated loading after threshold strain occurrence led to identification of such behavior as plastic shakedown. Undrained conditions of the test enabled one to find strain relaxation phenomenon which is characterized by a bigger total strain increment than plastic strain.

5. Predicting the possible behavior of soil specimen in the 100 000th cycle in undrained conditions we could state that resilient modulus will fall to the values obtained at threshold strain. With that phenomenon it is possible to make prognosis as regards the dissipation of excess water pressure, closing of hysteresis loop in plastic shakedown manner and end of plastic strain increment. Nevertheless, further studies with one million repeated loading cycles are needed to confirm such statements.

\section{REFERENCES}

[1] ARVin M.A., Askari F., FARZANeH O., Seismic behavior of slopes by lower bound shakedown theory, Computers and Geotechnics, 2012, 39, 107-115, DOI: 10.1016/j.compgeo.2011.08.001.

[2] Boulbibane M., PONTER A.R.S., The linear matching method for the shakedown analysis of geotechnical problems, International Journal for Numerical and analytical Methods in Geomechanics, 2006, 30(2), 157-179, DOI: 10.1002/nag.481.

[3] Boulbibane M., Weichert D., Application of shakedown theory to soils with non-associated flow rules, Mechanics Research Communications, 1997, 24(5), 516-519, DOI: 10.1016/S0093-6413(97)00056-6.

[4] Cunny R.W., Sloan R.C., Dynamic loading machine and results of preliminary small-scale footing tests, ASTM Special Technical Publication, 1961, 305, 65-77.

[5] GŁUCHOwsKi A., Estimating of shakedown limit for cohesive soils under cyclic loading from cCBR test, [in:] J. Bzówka (ed.), Wiedza i eksperymenty w budownictwie, 2014, 61-69.
[6] Hu C., Liu H., Huang W., Anisotropic bounding-surface plasticity model for the cyclic shakedown and degradation of saturated clay, Computers and Geotechnics, 2012, 44, 34-47, DOI: 10.1016/j.compgeo.2012.03.009.

[7] KalinOwSKa M., JASTRZĘBSKA M., Behaviour of cohesive soil subjected to low-frequency cyclic loading in straincontrolled tests, Studia Geotechnica et Mechanica, 2014, 36(3), 21-35, DOI: 10.2478/sgem-2014-0024.

[8] KOITER W.T., General theorems for elastic-plastic solids, [in:] I.N. Sneddon, R. Hill (eds.), Progress in Solid Mechanics, 1960, 167-221.

[9] Konig J.A., Shakedown of Elastic-Plastic Structures, Elsevier, Warszawa, 1987.

[10] Li H.X., YU H.S., A non linear programming approach to kinematic shakedown analysis of frictional materials, International Journal of Solids Structures, 2006, 43(21), 6594-6614, DOI: 10.1016/j.ijsolstr.2006.01.009.

[11] Melan E., Zur plastizitat des raumlichen Kontinuums, Ing. Arch., 1938, 19, 116-125.

[12] Nazzal M.D., Mohammad L.N., Austin A., Evaluation of the shakedown behavior of unbound granular base materials, Geo-Frontiers Congress, 2011.

[13] Ni J., IndRaratna B., Geng X.Y., CARTer J.P., RUJIKIATKAMJORN C., Radial consolidation of soft soils under cyclic loads, Computers and Geotechnics, 2013, 50, 1-5, DOI: 10.1016/jcompgeo.2012.11.011.

[14] PANDE G.N., Shakedown of foundations subjected to cyclic loads, [in:] O.C. Zienkiewicz, G.N. Pande (eds.), Soil Mechanics - Transient and Cyclic Loads, 1982, 469-489.

[15] CHINH P.D., Shakedown theory for elastic plastic kinematic hardening bodies, International Journal of Plasticity, 2007, 23(7), 1240-1259, DOI: 10.1016/j.compgeo.2012.11.011.

[16] PonTer A.R.S., Hearle A.D., Johnson K.L., Application of the kinematical shakedown theorem to rolling and sliding point contacts, Journal of the Mechanics and Physics of Solids, 1985, 33(4), 339-362.

[17] RaYmond G.P., Komos F.E., Repeated load testing of a model plane strain footing, Canadian Geotechnical Journal, 1978, 15(2), 190-201.

[18] SHARP R.W., BOOKer J.R., Shakedown of pavements under moving surface loads, Journal of Transportation Engineering, 1984, 110(1), 1-14.

[19] Sas W., GŁUChOwski A., Application of cyclic CBR test to approximation of subgrade displacement in road pavement, Acta Scientarum Polonorum-Architectura, 2013, 12(1), $51-61$.

[20] TaO M., Mohammad L.N., Nazzal M.D., Zhang Z., Wu Z., Application of shakedown theory in characterizing traditional and recycled pavement base materials, Journal of Transportation Engineering, 2010, 136(3), 214-222.

[21] Werkmeister S., Dawson A.R., Wellner F., Permanent deformation behavior of granular materials and the shakedown concept, Transportation Research Record: Journal of the Transportation Research Board, 2001, 1757(1), 75-81.

[22] Werkmeister S., Permanent deformation behavior of unbound granular materials, Doctoral dissertation, University of Technology, Dresden, Germany, 2003.

[23] WerKmeIster S., Shakedown analysis of unbound granular materials using accelerated pavement test results from New Zeland's CAPTIF facility, Geotechnical Special Publication, 2006, 154, Shanghai, China, 220-228.

[24] Yashuara K., Hirao K., Hyde A.F.L., Effects of cyclic loading on undrained strength and compressibility of clay, Soils and Foundations, 1992, 32(1), 100-116. 
[25] Yu H. S., Khong C. D., Wang J., Zhang G., Experimental evaluation and extension of a simple critical state model for sand, Granular Matter, 2005, 7(4), 213-225, DOI: 10.1007/s10035-005-0209-y.

[26] Yu H.S., Plasticity and Geotechnics, Springer, New York, 2006.
[27] Yu H.S., Hossain M.Z., Lower bound shakedown analysis of layered pavements using discontinuous stress fields, Computer Methods in Applied Mechanics and Engineering, 1998, 167(3), 209-222, DOI: 10.1016/S0045-7825 (98)00120-0. 